\title{
Effects of Angiogenic Factors and 3D- Microenvironments on Vascularization within Sandwich Cultures
}

\author{
Akihiro Nishiguchi ${ }^{1}$, Michiya Matsusaki $^{1}$, Yoshiya Asano $^{2}$, Hiroshi Shimoda $^{2}$ and Mitsuru Akashi ${ }^{1 *}$ \\ ${ }^{1}$ Department of Applied Chemistry, Graduate School of Engineering, Osaka University, 2-1 Yamada-oka, \\ Suita, 565-0871, Japan. \\ ${ }^{2}$ Department of Neuroanatomy, Cell Biology and Histology, Graduate School of Medicine, Hirosaki \\ University, 5 Zaifu, Hirosaki, 036-8562, Japan.
}

\section{CORRESPONDING AUTHOR FOOTNOTE}

*Author to whom correspondence should be addressed:

Mitsuru Akashi, Ph. D. Professor

Mailing address: 2-1 Yamada-oka, Suita 565-0871, Japan

Tel +81-6-6879-7356

Fax +81-6-6879-7359

E-mail: akashi@chem.eng.osaka-u.ac.jp 


\begin{abstract}
The in vitro fabrication of vascularized tissue is a key challenge in tissue engineering, but little is known about the mechanisms of blood capillary formation. Here we investigated the mechanisms of in vitro vascularization using precisely-controlled 3D-microenvironments constructed by a sandwich culture using the cell-accumulation technique. 3D-microenvironments controlled at the single layer level showed that sandwich culture between more than 3 fibroblast-layers induced tubule formation. Moreover, the secretion of angiogenic factors increased upon increasing the number of sandwiching layers, which induced highly dense tubular networks. We found that not only angiogenic factors, but also the 3D-microenvironments of the endothelial cells, especially apical side, played crucial roles in tubule formation in vitro. Based on this knowledge, the introduction of blood and lymph capillaries into mesenchymal stem cell (MSC) tissues was accomplished. These findings would be useful for the in vitro vascularization of various types of engineered organs and studies on angiogenesis.
\end{abstract}

Keywords: Artificial tissue engineering, Angiogenesis, Cytokine, ECM (extracellular matrix), Endothelial cell 


\section{Introduction}

A current key challenge in tissue engineering is in vitro vascularization of an engineered tissue that can be employed for clinically-relevant therapies and as a drug testing model. Blood capillaries, which are composed of endothelial monolayer, pericytes and fibroblasts, maintain the metabolic activities and functions of organs through the transportation of nutrients and oxygen [1]. The introduction of these vasculatures into engineered tissues has advantages to avoid necrosis of the inner tissues and to enhance their functions through cellular signalling [2,3]. To develop functional blood capillaries, many attempts such as a 3-dimensional (3D) culture of endothelial cells in hydrogels composed of extracellular matrix (ECM) [4,5], the fixation of angiogenic factors into scaffolds [6-11], cell sheet engineering for transplantable tissues [12-14], and micro channel models with flow [15-17] have been reported. Although these systems are powerful methods to construct vascularized tissues, they need complicated devices and procedures for the vascularization, and the potential limitations to recreate both the structures and functions of living tissues in vitro still remain. This is obviously caused by a poor understanding of the mechanisms responsible for the formation of blood-capillary networks in vitro, and therefore the requirements for vascularization should be clarified, such as the microenvironments for cell culture, the species and stiffness of the surrounding tissue, and the effects of angiogenic factors secreted under hypoxia.

Recently, we developed the rapid construction of 3D-vascularized multilayered tissues by the formation of ECM nanofilms onto single surfaces using layer-by-layer assembly [18]. Less than 10 nm thickness of ECM films composed of fibronectin and gelatin (FN-G) allowed all cells to adhere to each other through interactions between the FN-G nanofilms and the cell membrane proteins to create various types of tissues such as blood vessel walls and livers [19-22]. Using this technique and a sandwich culture, highly-dense and homogeneous endothelial tubular networks were formed in fibroblast tissues. We have confirmed that this blood-capillary model can work as a model to test the differentiation stages of cartilage-like tissue [23]. 
Here, we report the biochemical and physical effects that can induce in vitro vascularization in

engineered 3D-microenvironments (Fig. 1a). Since the cell-accumulation technique is able to control the number of tissue layers, we could investigate the role of the $3 \mathrm{D}$-microenvironment at the level of a single cell layer. We tested the effect of the fibroblast layer number, angiogenic factors secreted under hypoxic conditions, and 3D-microenvironments on the tubule formation of endothelial cells in vitro. Furthermore, the angiogenesis and lymphangiogenesis in human adipose-derived mesenchymal stem cell (MSC) tissues were also evaluated same as fibroblasts. 


\section{Materials \& methods}

\subsection{Materials}

All of the chemicals were used without further purification. Fibronectin (FN) from bovine plasma $\left(M_{\mathrm{w}}=4.6 \times 10^{5}\right)$ and vascular endothelial growth factor (VEGF) were purchased from Sigma-Aldrich (MO, USA). Dulbecco's modified eagle medium (DMEM), gelatin $(\mathrm{G})\left(M_{\mathrm{w}}=1.0 \times\right.$ $10^{5}$ ), tris(hydroxymethyl)aminomethane hydrochloride (Tris- $\mathrm{HCl}$ ), $10 \%$ formalin solution, and $4 \%$ paraformaldehyde (PFA)/phosphate buffer solution were purchased from Wako Pure Chemical Industries (Osaka, Japan). $\varepsilon$-Lys $\left(M_{\mathrm{w}}=4700\right)$ was kindly donated by CHISSO Corporation (Chiba, Japan). The monoclonal mouse anti-human CD31 antibody and the monoclonal mouse anticollagen type IV were purchased from Dako (Glostrup, Denmark). Goat anti-mouse Alexa Fluor 488- and 546-conjugated IgG, 4',6-diamidino-2-phenylindole dihydrochloride (DAPI), cell tracker green, Triton X, fetal bovine serum (FBS), human adipose-derived mesenchymal stem cells (MSC), and MesenPRO RS medium were purchased from Life Technologies (CA, USA). The mouse antihuman VEGF antibody and the ELIZA assay kits for human VEGF, human hepatocyte growth factor (HGF) and human basic fibroblast growth factor (bFGF) were purchased from R\&D systems (MN, USA). The cell culture insert with a $0.4 \mu \mathrm{m}$ pore size was purchased from BD bioscience (NJ, USA) and Corning (NY, USA). Normal human dermal fibroblast (NHDF), human umbilical vein endothelial cell (HUVEC), human umbilical artery endothelial cell (HUAEC), human dermal lymphatic microvascular endothelial cell (LEC), and endothelial growth medium (EGM-2MV) were purchased from Lonza (NJ, USA). Mouse 10T1/2 and 3T3 cells were purchased from ATCC (VA, USA). The mouse pancreatic fibroblast cells (K643f) and mouse 3T3 fibroblast cells were kindly donated by Dr. M. R. Kano from Okayama University and Dr. K. Miyazono from Tokyo University.

\subsection{Construction of the blood-capillary model by cell-accumulation technique}


The NHDFs after trypsinization were suspended in $0.04 \mathrm{mg} / \mathrm{ml}$ of $\mathrm{FN}$ and $\mathrm{G} / \mathrm{Tris}-\mathrm{HCl}$

solution $(50 \mathrm{mM}, \mathrm{pH}=7.4)$, and alternately incubated for 1 minute using a Micro-tube Rotator (MTR-103, AS ONE, Japan) with a washing step. The centrifugation was performed at $200 \mathrm{xg}$ for 1 minute at each step. After 9 steps of coating, about $10 \mathrm{~nm}$ of the FN-G nanofilms were coated onto single cell surfaces. The cells were suspended in $0.3 \mathrm{ml}$ of DMEM with $10 \% \mathrm{FBS}$, and were seeded onto 24 well trans-well inserts with a semipermeable membrane, and $1.4 \mathrm{ml}$ of media was added into the microplates. After 1 hour of incubation, another $1 \mathrm{ml}$ of media was added to each well to connect the inner and outside media of the inserts, and the cells were then incubated in $5 \% \mathrm{CO}_{2}$ at $37{ }^{\circ} \mathrm{C}$. After 1 day, NHDF tissues from a monolayer to 20 layers thickness were constructed. A $1 \mathrm{x}$ $10^{5}$ cells/layer aliquot was used for the 24 well inserts, and $2.5 \times 10^{5}$ cells/well for the 12 well inserts. In the same manner, $1 \times 10^{5}$ HUVEC cells were coated with FN-G nanofilms, and were seeded onto each NHDF tissue. The HUVECs adhered within 1 day to form a monolayer HUVECNHDF tissues. Moreover, the NHDFs coated with FN-G nanofilms accumulated on them, and thus a sandwich culture was performed. Normally, these cells were cultured for 1 week and fixed with a 4\% PFA buffer solution for immunostaining. The NHDFs (passages: 4-10) were cultured in DMEM with 10\% FBS. The HUVECs, HUAECs, and LECs (passages: 3-7) were cultured in EGM-2MV. The MSCs (passages: 3-7) were cultured in MesenPRO RS medium.

\subsection{Immunofluorescent analysis}

The NHDFs were stained with cell tracker green, and the endothelial cells were immunostained with an anti-CD31 antibody. Briefly, the tissues were permeabilized with $0.2 \%$ Triton-X for 15 minutes and blocked with 1\% BSA/PBS for 1 hour. The tissues were then incubated with the primary antibodies (1:50) for 1 hour. After a washing step, the secondary antibodies (1:200) were added to the tissues. The tissues were finally observed by confocal laser scanning microscopy (CLSM, FLUOVIEW FV10i, Olympus, Japan) and confocal disk scan microscopy (DSU-IX81-SET, Olympus, Japan). For immunohistological observation of the blood-capillary 
models, an anti-Von Willebrand factor antibody was used. For measurements of the tubular lengths, cell numbers, branching points, mean lengths, and occupied area percentage, Metamorph software version 6.2r6 (Molecular Devices, USA) and WimTube (Wimasis, Germany) were used.

\subsection{Oxygen partial pressure measurements}

The oxygen partial pressure in the media was measured by an oxygen partial pressure meter (PO2-150S, Eikoukagaku, Tokyo, Japan). This device measured current value of oxygen on the surface of the electrode (POE-20W, Eikoukagaku, Tokyo, Japan) under a suitable voltage using the polarography principle to estimate oxygen partial pressure. The measurements were performed at a time point soon after seeding the NHDFs into the insert to form the $1 \mathrm{~L}, 4 \mathrm{~L}, 8 \mathrm{~L}$, and $4 \mathrm{~L}-1 \mathrm{~L}-4 \mathrm{~L}$ tissues. The oxygen partial pressure of the medium without tissue was set as $150 \mathrm{mmHg}$. After 24 hours, the media were changed, and the measurements were continued again.

\subsection{Reverse transcription PCR analysis}

The total RNA from the 1L, 4L, and 8L-NHDF tissues was extracted using a RNA micro scale kit (Life Technologies, CA, USA) according to the manufacturer's protocol. cDNA was prepared from $200 \mathrm{ng}$ of total RNA using a cDNA synthesis kit. The reverse transcription polymerase chain reaction (RT-PCR) was performed with Taqman gene expression assays. The gene expression levels of the following targets were measured: VEGFA, HGF, bFGF, and glyceraldehyde 3-phosphate dehydrogenase (GAPDH). The relative quantification was performed by a comparative $\mathrm{C}_{\mathrm{T}}$ method. The obtained gene expressions were normalized to GAPDH used as a house keeping gene.

\subsection{ELISA measurement and the blocking test}


VEGF, HGF, and bFGF from 1L-, 4L-, and 8L-tissues were measured by ELISA assay. A

$2.3 \mathrm{ml}$ aliquot of the supernatant from tissues in the 24 well inserts were collected, and added into a microplate from each ELISA assay kit. For the blocking tests, 4L-1L-4L tissues were exposed to media containing $100 \mathrm{ng}$ of anti-VEGF antibody, and incubated for 1 week while changing the media every day. The tissues were then immunostained with anti-CD31 antibodies and observed by CLSM.

\subsection{Fabrication of MSC tissue with blood-and lymph-capillary networks}

4L-MSC tissues were constructed on 1L-HUVEC in the same manner as the NHDFs to obtain 4L-MSC-1L-HUVEC tissues after 3 days of incubation. To culture 4L-1L MSC tissues under hypoxic conditions, the medium in the insert was set at $0.3 \mathrm{ml}$, and the medium in the plate was set to $1.4 \mathrm{ml}$ without connecting the medium between the insert and plate.

\subsection{Statistical analysis}

All data were expressed as means \pm SD unless otherwise specified. For the PCR analysis, the values represent the mean \pm SD from three independent experiments. Statistical comparisons between groups were analyzed by Student's t-test. Statistical differences from the PCR and ELISA analyses were determined by Tukey's multiple comparison test. A p value $<0.05$ was considered to be statistically significant. 


\section{Results}

\subsection{Effect of the number of NHDF layers on tubular formation by sandwich culture}

As shown by the CLSM observations from Fig. 1b, highly dense and homogeneous tubular networks were formed by a sandwich culture of HUVECs between 4L- NHDF tissues (4L-1L-4L) after 7 days in DMEM. On the other hand, tubular networks were not seen in the 1L-4L tissues, and almost all of the HUVECs disappeared after 7 days. Furthermore, in the case of a mixture of NHDFs and HUVECs, tubular structures were partially confirmed, but they were not homogeneous and did not connect with each other densely. These results suggest that a sandwich culture between NHDF multilayers would be the most suitable method to construct blood-capillary models. The density of the tubular networks could be controlled by adjusting the density of the sandwiched HUVECs (Fig. S1). Similarly, the components of the nanofilms on the cell surfaces affected the density of the tubular networks and FN and $\varepsilon$-Lys nanofilms containing cationic polymers reduced the tubular networks (Fig. S2). Furthermore, sandwiching HUAECs or LECs instead of HUVECs allowed them both to successfully form tubular networks in the whole tissue (Fig. S3) [24]. To investigate the relationship between the number of NHDF layers and the formation of tubular structures, structural observation of the HUVECs sandwiched between the different numbers of NHDF layers was performed by CLSM (Fig. 2 and Fig. S4). Each tissue was constructed by a sandwich culture of HUVECs between 1L- to 10L-NHDF layers. As a result, more than 3 layers of NHDF tissues induced morphological change in the HUVECs to form tubular networks (Fig. 2a). A quantitative analysis of the tubular structures showed that the total tubular length and number increased upon increasing the number of sandwiching NHDF layers, especially with more than 4Ltissues (Fig. 2b-c). Many branching points of the tubular structures were also seen in sandwich culture using thick NHDF tissues, and the mean tubular lengths estimated from the tubular length between the branching points were almost the same in all samples (Fig. 2d-e).

\subsection{Structural observations of HUVEC networks}


We performed immunohistochemistry with an anti-Von Villebrand factor antibody (Fig. 3a-

b). There were many lumenal structures distributed three-dimensionally in the tissues, and the area of the HUVECs and lumen increased upon increasing the number of NHDF layers, as well as the tubular length and number in Fig. 2 (Fig. S5). Type IV collagen, which is one of the components of the basement membrane, was strongly expressed around the lumens of the HUVEC (Fig. 3d,e). Through the deposition of the perivascular ECM (black arrow) and the formation of the endoplasmic reticulum (red arrow), the appropriate apical-basal polarity of the HUVECs was confirmed. The perivascular ECM with positive staining of collagen type IV would be secreted from NHDFs and HUVECs during the sandwich culture. We confirmed the structures of the ECM and the formation of adherens junctions by immunofluorescent and transmission electron microscopy (TEM) observations (Fig. 3f,g). The HUVECs attached tightly with each other, and formed lumenal structures which were stabilized through adherens junctions as well as blood vessels in the living body.

\subsection{Measurements of hypoxic conditions and angiogenic factors}

To measure hypoxia in the 3D-microenvironment, the oxygen partial pressure in the media was measured during incubation (Fig. 4a). As a result, the oxygen partial pressure of the 8L and 4L1L-4L tissues decreased rapidly to half of the starting value within several hours. Once the oxygen partial pressures returned to their original values by changing the media after 24 hours, it decreased again within 3 hours. To check the gene expression of angiogenic factors such as VEGFA, HGF and basic fibroblast growth factor under hypoxic conditions, real time RT-PCR measurements were performed (Fig. 4b). The gene expression of VEGF and HGF in 4L-tissues were 1.5 to 2-fold higher than that of 1L-tissues after 24 hours of incubation, whereas the gene expression of bFGF decreased upon increasing the number of NHDF layers. Three types of angiogenic factors secreted from each tissue after 24 hours were measured by ELISA assays. The secretion of VEGF, HGF, and bFGF drastically increased upon increasing the number of NHDF layers (Fig. 4c-e). In particular, the 8L- 
tissue secretion of VEGF, which is one of the most important factors for angiogenesis through the

activation of migration, proliferation, and differentiation of endothelial cells, showed a more than 60-fold increase as compared to 1L-tissues. To confirm the effect of VEGF on tubule formation, an anti-VEGF antibody was used as a blocking experiment. We exposed the blood-capillary models to the media containing $100 \mathrm{ng}$ of anti-VEGF antibody per sample. This value is equivalent to 10 times as much as VEGF secreted from 8L-NHDF tissues estimated form ELISA result in Fig. 4c. As a result, the HUVECs did not form very dense and homogeneous tubular structures by inhibiting the functions of VEGF, thus indicating that angiogenic factors played important roles in tubule formation (Fig. 4f-g). Furthermore, to understand the effects of long-term culture on angiogenesis, the gene expression of angiogenic factors in 1L-, 5 L-, 10L-, and 20L-NHDF tissues after 2, 7, 10, and 14 days of incubation were analyzed by RT-PCR measurements (Fig. 5 and Fig. S6). Comparing the gene expressions of the NHDF multilayers versus NHDF monolayers, all gene expressions showed drastic increases (up to a 40-fold increase) in contrast with the gene expression of NHDF tissues after 1 day of incubation. The gene expressions increased with increasing layer number, and these high gene expression levels were maintained even after 14 days of incubation.

\subsection{Effect of 3D-microenvironments on tubular formation}

To understand whether the 3D-microenvironment around the HUVECs is essential for tubule formation, the HUVEC monolayers were cultured under various conditions (Fig. 6a). Even though the HUVEC monolayers were exposed to media containing a sufficient amount of VEGF (10 ng) or collected from NHDF multilayers that secreted angiogenesis factors, there were no morphological changes, and the HUVECs maintained their cobble stone structures after 5 days. Next, we tried to investigate what microenvironment could induce tubular formation in detail. To do this, 1L-4L, 2L-1L-2L, and 4L-1L tissues were constructed, and their HUVEC structures were observed. To evaluate the effects of only the 3D-microenvironment, the total number of NHDF layers was standardized to 4 layers, which means that the same amount of angiogenic factors 
was in each sample, although the local position of NHDFs was different in each tissue. The HUVECs were put at the top (1L-4L), middle (2L-1L-2L), and bottom (4L-1L) of 4L-tissues (Fig. 6b-c). As a result, only the 4L-1L tissues induced tubular formation of the HUVECs, even though the total number of NHDF layers was less than 4 layers.

\subsection{Fabrication of multilayered MSC tissues with blood-and lymph-capillary networks}

Finally, we fabricated MSC vasculogenesis models based on knowledge obtained from the introduction of blood capillaries into fibroblast tissues. Since the angiogenic factors secreted from the surrounding tissues under hypoxic conditions and the 3D-microenvironments above the HUVECs play important roles in vascularization (Fig. 7a), we exposed the 4L-MSC-1L-HUVEC tissues to hypoxic conditions, which satisfied above requirements. To induce the hypoxic conditions, MSC tissue was cultured in a lower volume of media as compared to the control. As a result, the oxygen partial pressure of the 4L-MSC tissues in the lower volume of culture media decreased significantly during the initial 3 hours of incubation (Fig. 7b). Next, we constructed 4 types of MSC tissues $(1 \mathrm{~L}-1 \mathrm{~L}, 4 \mathrm{~L}-1 \mathrm{~L}, 4 \mathrm{~L}-1 \mathrm{~L}$ cultured under hypoxia, and 4L-1L cultured in VEGF-containing media) and checked the degree of vascularization of the HUVECs after 3 days of incubation by anti-CD31 antibody immunostaining. HUVECs in 1L-1L tissue did not form tubular structures, as well as the NHDF tissue. Although the 4L-1L tissues formed HUVEC tubular networks, there were many discontinuous structures and defects (Fig. 7c). On the other hand, the 4L-1L tissues under hypoxia have more continuous and homogeneous tubular networks and the area of the HUVEC networks was greater than the 4L-1L tissue, suggesting that the hypoxic conditions promoted tubular formation in the MSC tissue (Fig. 7c-d). There were no significant differences between the 4L-1L as a control and 4L-1L in VEGF-containing media, even though angiogenic factors were added to the media.

Furthermore, this vascularization method was applied to the fabrication of a lymph-capillary model of MSCs. In the same manner as HUVEC tubular formation, the 4L-MSC-1L-LEC tissue 
was constructed. As shown in the fluorescent image of the 4L-MSC-1L-LEC tissue immunostained with an anti-CD31 antibody in Supplementary Fig. 9a, lymphatic tubular structures were successfully formed and they had clear lumenal images after 3 days of incubation. Amazingly, when HUVECs and LECs were introduced into the MSC tissue at the same time and at the same plane, the HUVEC and LEC tubular networks were formed separately in the MSC tissue (Fig. S9b), which are in agreement with the results of the NHDF sandwich culture [24]. 


\section{Discussion}

We have reported a bottom-up approach to construct 3D-vascularized tissues by the cellaccumulation technique using ECM nanofilms on single cell surfaces [18]. During tubule formation, the HUVECs spontaneously assembled and could form networks by adjusting the culture conditions such as the 3D-microenvironment, hypoxia conditions, and angiogenic factors, as well as the angiogenesis process in the body. TEM images clearly revealed the adherens junctions between HUVECs in the networks. Interestingly, we recently found HUVECs formed the developed adherens junctions, while LEC displayed irregular shape, loose adhesive connection and gap formation [24], suggesting FN-G nanofilms with mesh-work fiber structures [25] did not inhibit the formation of adherens junctions to recreate the junction structures of blood and lymph vessels in vivo. As shown in Fig. 2, we found that a sandwich culture of HUVECs of more than 3L-NHDF tissues was required for tubule formation. We focused on the roles of angiogenic factors to promote angiogenesis. Angiogenic factors such as VEGFA, HGF, and bFGF are secreted from surrounding tissues that lack nutrients and oxygen under hypoxic conditions [26]. Since these angiogenic factors are known to activate the functions of endothelial cells to induce migration, proliferation, and differentiation, they have been widely employed by fixation in hydrogels to achieve in vitro vascularization. As shown in Fig. 4 and 5, the increase in the number of NHDF layers resulted in an increase in angiogenic factor secretion through the decreased oxygen concentration, suggesting that angiogenic factors secreted from the NHDF multilayers caused tubule formation through the activation of HUVECs. Therefore, we assumed that the total amount of angiogenic factors would be important for in vitro vascularization. Actually, all of the angiogenic factors measured in this study were secreted at much higher concentrations from the NHDF multilayers than from the NHDF monolayer, and the blocking experiments showed the importance of VEGFA for tubule formation (Fig. 4 d-e). The reason why the 3D-engineered tissues produced a greater amount of angiogenic factors is believed to be various 3D-effects such as central hypoxia, 
3D-cell adhesion, and stiffness, indicating that this 3D-technology can mimic the angiogenesis process in a living body [27-29].

Although the secretion of angiogenic factors plays a crucial role in tubule formation, when the HUVEC monolayers were exposed to media containing VEGF or collected from NHDF multilayers cultured separately, they did not change their morphologies in spite of the adequate angiogenic factors (Fig. 6a). These results revealed that not only angiogenic factors, but also 3Dmicroenvironments, are essential to start tubule formation. To confirm the requirements for tubule formation in detail, we observed the structures of HUVECs arranged in the top, middle, and bottom of 4L-NHDF tissues. Only the 4L-1L tissues formed tubular structures, even though the amount of angiogenic factors was almost the same as the $1 \mathrm{~L}-4 \mathrm{~L}$ and $2 \mathrm{~L}-1 \mathrm{~L}-2 \mathrm{~L}$ tissues, indicating that the microenvironments above the HUVECs determined whether in vitro vascularization occurs. These results can be understood by the vertical migration and assembly of HUVECs in the NHDF tissues. Sandwiched between the 2L-NHDF layers, the HUVECs migrated to the top of the tissues and then detached from tissue because we used DMEM without any cytokines. On the other hand, the arrangement of the greater than 4L-NHDF tissues above the HUVECs led to tubule formation, which is believed to be related to the distance from the HUVEC to the top of the NHDF tissues. Kino-oka and co-workers reported that HUVEC network formation depends on the HUVECs encountering and making connections when 5L myoblast sheets were placed on various densities of HUVEC monolayer [30]. Therefore, HUVEC assembly occurred effectively as compared to vertical migration when the arranged thick NHDF tissues on the HUVEC monolayer formed high density tubular networks. Currently, there are some reports on the construction of vascularized tissues by 3D-culture in scaffolds where various cytokines were fixed, co-cultured with pericytes, and cell sheet engineering. However, the detailed requirements of in vitro vascularization are still unclear, because these methods have limitations in controlling the 3D-microenvironments of the cells at the single layer level. Since this cell-accumulation technique is able to control the 3D-culture conditions at the single layer level without complicated procedures, this method would be useful to 
recreate 3D-microenvironments for in vitro vascularization, and to investigate the mechanisms of tubule formation.

Furthermore, when applying these results to MSC tissues, the vascularized MSC tissues were successfully fabricated in vitro. Comparing to NHDFs, MSC tissues might require higher hypoxic condition media because the section of angiogenic factors significantly depends on cell type. Both the 3D-microenvironments above the HUVECs and the hypoxic conditions that can induce angiogenic factor secretion from MSCs contributed to the formation of blood- and lymphcapillary networks in the MSC tissues. To the best of our knowledge, this is the first example of the fabrication of MSC tissues with blood- and lymph-capillary networks. This knowledge can be used for the vascularization of other tissues, such as the liver and pancreas [31]. On the other hand, the cell types and their derivation strongly influenced the cell behaviors and cell-cell interactions. For example, human pancreatic fibroblast cells (K643f) and mouse 3T3 fibroblast cells did not induce HUVEC tubule formation during sandwich culture (Fig. S7). Therefore, the appropriate 3Dmicroenvironment for endothelial cells should be prepared to introduce blood capillaries into other tissues. These in vitro blood capillary models have potential as angiogenesis assays, especially for tumor angiogenesis assays which for cancer therapy, and allow enable the evaluation of the potential effects of drugs and drug carriers in vitro [32-34]. 


\section{Conclusions}

In summary, we investigated the effects of 3D-microenvironments and angiogenic factors on in vitro vascularization by sandwich culture using the cell-accumulation technique. By increasing the NHDF layer number, the gene expression and angiogenic factor secretion of the NHDF multilayers under hypoxic conditions increased, as compared to NHDF monolayers, to promote tubule formation of the HUVECs. We found that the 3D-microenvironments around the HUVECs, especially above the HUVECs, were important for tubule formation because more than 4L-NHDF tissues generated tubular networks, but less than 2L-NHDF tissues did not. Furthermore, the introduction of blood- and lymph-capillary networks into the MSC tissues was also achieved by altering the 3D-microenvironments for the first time. These findings would be useful for tissue engineering that needs the introduction of blood vessels, and for investigations into biological mechanisms such as tumor angiogenesis. 


\section{Acknowledgments}

1

This work was supported by the NEXT Program (LR026), a Grant-in-Aid for Scientific Research (S), and the SENTAN-JST Program. We also thank Akiko Seo for her technical assistance. 


\section{References}

(1) Isenberg BC, Wong JY. Building structure into engineered tissues. Materials Today 2006;9:54-60.

(2) Radisic M, Yang L, Boublik J, Cohen RJ, Langer R, Freed LE, et al. Medium perfusion enables engineering of compact and contractile cardiac tissue. Am J Physiol Heart Circ Physiol 2004;286:507516.

(3) Lammert E, Cleaver O, Melton D. Induction of pancreatic differentiation by signals from blood vessels. Science 2001;294:564-567.

(4) Folkman J, Haudenschild C. Angiogenesis in vitro. Nature 1980;288:551-556.

(5) Madri JA, Williams SK, Wyatt T, Mezzio C. Capillary endothelial cell cultures: Phenotypic Modulation by matrix components. J Cell Biol 1983;97:153-165.

(6) Chiu LLY, Radisic M. Scaffolds with covalently immobilized VEGF and Angiopoietin-1 for vascularization of engineered tissues. Biomaterials 2010;31:226-241.

(7) Moon JJ, Saik JE, Poché RA, Leslie-Barbick JE, Lee SH, Smith AA, et al. Biomimetic hydrogels with pro-angiogenic properties. Biomaterials 2010;31:3840-3847.

(8) Levenberg S, Rouwkema J, Macdonald M, Garfein ES, Kohane DS, Darland DC, et al. Engineering vascularized skeletal muscle tissue. Nat Biotechnol 2005;23:879-884.

(9) Armulik A, Genové G, Betsholtz C. Pericytes: Developmental, physiological,and pathological perspectives, problems, and promises. Dev Cell 2011;21:193-215.

(10) Koike N, Fukumura D, Gralla O, Au P, Schechner JS, Lain RK. Creation of long-lasting blood vessels. Nature 2004;428:138-139.

(11) Grainger SJ, Putnam AJ. Assessing the permeability of engineered capillary networks in a 3D culture. PLoS ONE 2011;6: e22086.

(12) Sasagawa T, Shimizu T, Sekiya S, Haraguchi Y, Yamato M, Sawa Y, et al. Design of prevascularized three-dimensional cell-dense tissues using a cell sheet stacking manipulation technology. Biomaterials 2010;31:1646-1654.

(13) Asakawa N, Shimizu T, Tsuda Y, Sekiya S, Sasagawa T, Yamato M, et al. Pre-vascularization of in vitro three-dimensional tissues created by cell sheet engineering. Biomaterials 2010;31:39033909. 
(14) Haraguchi Y, Shimizu T, Sasagawa T, Sekine H, Sakaguchi K, Kikuchi T, et al. Fabrication of

functional three-dimensional tissues by stacking cell sheets in vitro. Nat Protoc 2012;7:850-858.

(15) Miller JS, Stevens KR, Yang MT, Baker BM, Nguyen DHT, Cohen DM, et al. Rapid casting of patterned vascular networks for perfusable engineered three-dimensional tissues. Nat Mater 2012;11:768-774.

(16) Zheng Y, Chen J, Craven M, Choi NW, Totorica S, Diaz-Santana A, et al. In vitro microvessels for the study of angiogenesis and thrombosis. Proc Natl Acad Sci U S A 2012;109:9342-9347.

(17) Yoshida H, Matsusaki M, Akashi M. Multilayered blood capillary analogs in biodegradable hydrogels for in vitro drug permeability assays. Adv Funct Mater 2013;23:1736-1742.

(18) Nishiguchi A, Yoshida H, Matsusaki M, Akashi M. Rapid construction of three-dimensional multilayered tissues with endothelial tube networks by the cell-accumulation technique. Adv Mater 2011;23:3506-3510.

(19) Matsusaki M, Kadowaki K, Nakahara Y, Akashi M. Fabrication of cellular multilayers with nanometer-sized extracellular matrix films. Angew Chem Int Ed 2007;46:4689-4692.

(20) Matsusaki M, Ajiro H, Kida T, Serizawa T, Akashi, M. LbL assembly through weak interactions and their biomedical applications. Adv Mater 2012;24:454-474.

(21) Matsusaki M, Kadowaki K, Adachi E, Sakura T, Yokoyama U, Ishikawa Y, et al. Morphological and histological evaluations of 3D-layerd blood vessel constructs prepared by hierarchical cell manipulation. J Biomater Sci Polymer Edn 2012;23:63-79.

(22) Matsusaki M, Sakaue K, Kadowaki K, Akashi M. Three-dimensional human tissue chips fabricated by rapid and automatic inkjet cell printing. Adv Healthcare Mater 2013;2:534-539.

(23) Sasaki J, Matsumoto T, Egusa H, Matsusaki M, Nishiguchi A, Nakano T, et al. In vitro reproduction of endochondral ossification using a 3D mesenchymal stem cell construct. Integrat Biol 2012;4:12071214.

(24) Asano Y, Nishiguchi A, Matsusaki M, Okano D, Saito E, Akashi M, et al. Ultrastructure of blood and lymphatic vascular networks in three-dimensional cultured tissues fabricated by ECM nanofilm-based cell accumulation technique. Microscopy, Ms: MICRO-2013-00063.R1.

(25) Kadowaki K, Matsusaki M, Akashi M. Control of cell surface and functions by layer-by-layer nanofilms. Languir 2010;26:5670-5678. 
(26) Harris AL. Hypoxia - A key regulatory factor in tumor growth. Nat Rev Cancer 2002;2:38-47.

(27) Cukierman E, Pankov R, Stevens DR, Yamada KM. Taking cell-matrix adhesions to the third dimension. Science 2001;294:1708-1712.

(28) Discher DE, Janmey P, Wang Y. Tissue cells feel and respond to the stiffness of their substrate. Science 2005;310:1139-1143.

(29) Fischbach C, Chen R, Matsumoto T, Schmelzle T, Brugge JS, Polverini PJ, et al. Engineering tumors with 3D scaffolds. Nat Methods 2007;4:855-860.

(30) Nagamori E, Ngo TX, Takezawa Y, Saito A, Sawa Y, Shimizu T, et al. Network formation through active migration of human vascular endothelial cells in a multilayered skeletal myoblast sheet. Biomaterials 2013;34:662-668.

(31) Kaufman-Francis K, Koffler J, Weinberg N, Dor Y, Levenberg S. Engineered vascular beds provide key signals to pancreatic hormone-producing cells. PLoS ONE 2012;7:e40741.

(32) Bergers G, Benjamin LE. Tumorigenesis and the angiogenic switch. Nat Rev Cancer 2003;3:401410.

(33) Smalley KSM, Lioni M, Noma K, Haass NK, Herlyn M. In vitro three-dimensional tumor microenvironment models for anticancer drug discovery. Expert Opin Drug Discov 2008;3:1-10.

(34) Peer D, Karp JM, Hong S, Farokhzad OC, Margalit R, Langer R. Nanocarriers as an emerging platform for cancer therapy. Nat Nanotechnol 2007;2:751-760. 
January 31, 2014

Dear Editor for Biomaterials:

Thank you to the referees for careful consideration of the manuscript. We have enclosed herewith the revised manuscript (Article) entitled "Effects of Angiogenic Factors and 3D-Microenvironments on Vascularization within Sandwich Cultures" by Akihiro Nishiguchi, Michiya Matsusaki, Yoshiya Asano, Hiroshi Shimoda and Mitsuru Akashi*. Manuscript jbmt26784R1.

Following the very helpful comments of the referees, we have revised our manuscript carefully. I am enclosing a list of the modifications of the original manuscript and our replies to the comments of reviewers.

We hope that you will consider this revised version suitable for publishing in Biomaterials.

Thanking you in advance for all the troubles.

Sincerely yours

Mitsuru Akashi, Ph.D. Professor

Department of Applied Chemistry,

Graduate School of Engineering,

Osaka University

2-1 Yamada-oka, Suita, Osaka 565-0871, Japan

Phone: +81-6-6879-7356, Fax: +81-6-6879-7359

E-mail: akashi@chem.eng.osaka-u.ac.jp 


\section{Answers to Reviewers}

We read your comments carefully, and made some modification to improve. We hope this revised manuscript to meet your suggestion. Please see the following section.

\section{MANDATORY EDITOR'S REQUIREMENTS:}

I acknowledge receipt of your revised manuscript. I can accept all of your change except for the introduction. You say that you have complied with my request to avoid discussing results in the Introduction, but now you finish the section with the sentence ' Based on these results, the introduction of blood- and lymph-capillary networks into human adipose-derived mesenchymal stem cell (MSC) tissues was achieved for the first time'. This is exactly what I do not want. Please delete this sentence.

Answer: Thank you for your suggestion. We deleted the sentence in the introduction and improved the sentences in the introduction and conclusion sections based on your comments.

Page 2, line 6: Furthermore, the angiogenesis and lymphangiogenesis in human adipose-derived mesenchymal stem cell (MSC) tissues were also evaluated same as fibroblasts.

Page 15, line 8: Furthermore, the introduction of blood- and lymph-capillary networks into the MSC tissues was also achieved by altering the 3D-microenvironments for the first time. 


\section{Figure captions}

Fig. 1. In vitro vascularization by sandwich culture using the cell accumulation technique. (a) Schematic illustration of the fabrication process of the endothelial tubule networks by the cell-accumulation technique. (b) CLSM cross-section images of 1L-4L tissue, 4L-1L-4L tissue, and a mixture of NHDFs and HUVECs after 7 days of incubation. The HUVECs were immunostained with an anti-CD31 antibody (red), and the NHDFs were labeled with CellTracker green (green).

Fig. 2. Effect of the number of NHDF layers on tubule formation. (a) CLSM images of blood-capillary models constructed by a sandwich culture of HUVECs between 1L- to 10L-NHDF tissues for 7 days. (b-e) Quantification of the total tubule length in all areas, the total tubule number, the number of branching points, and the mean tubule length of the HUVEC networks $(n=3)$. $\dagger \dagger$ : Tubular networks were not confirmed in $2 \mathrm{~L}$-tissues. ${ }^{*} P<0.05$, ${ }^{* *} P<0.01$ when compared with $4 \mathrm{~L}$.

Fig. 3. Immunohistological and TEM observations. Immunohistological images of (a) $4 \mathrm{~L}-1 \mathrm{~L}-4 \mathrm{~L}$ and (b) $10 \mathrm{~L}-1 \mathrm{~L}-10 \mathrm{~L}$ tissues immunostained with an anti-Von Willebrand factor antibody. (c) TEM image of the 10L-1L-10L tissues after 7 days of incubation. Structural analysis by (d) immunohisitological and (e) TEM observations of basement membranes and (f) immunofluorescent and (g) TEM observations of adherens junctions in 10L-1L-10L tissues. An anti-collagen type IV antibody and an anti-VE cadherin antibody were used for the immunostaining experiments. The black arrows denote the deposition of ECM and the red arrows show the formation of the endoplasmic reticulum. N: nucleus, Fb: fibroblast, Hv: lumen of HUVEC.

Fig. 4. Gene expression and secretion of angiogenic factors under hypoxic conditions. (a) Measurements of the oxygen partial pressure in the media of $1 \mathrm{~L}, 4 \mathrm{~L}, 8 \mathrm{~L}$, and $4 \mathrm{~L}-1 \mathrm{~L}-4 \mathrm{~L}$ tissues. (b) Relative gene expression and (c-e) ELISA analysis of the VEGFA, HGF, and bFGF levels of 1L-, 4L-, and 8L-NHDF tissues after 24 hours of incubation $(n=3)$. The transcripts were normalized to GAPDH. (f) CLSM images and $(\mathrm{g})$ the area of the tubule networks in $10 \mathrm{~L}-1 \mathrm{~L}-10 \mathrm{~L}$ tissues cultured without and with an anti-VEGF antibody $(\mathrm{n}=3)$. ${ }^{*} P<0.05,{ }^{* *} P<0.01$ when compared with $1 \mathrm{~L}, 4 \mathrm{~L}$, or control (Tukey's multiple comparison test).

Fig. 5. Effect of long-term culture on angiogenic factor expression. The relative gene expression of (a) VEGFA, (b) HGF, and (c) bFGF of the NHDF multilayers after 2, 7, 10, and 14 days of incubation $(n=3)$. The transcripts were normalized to GAPDH. ${ }^{*} P<0.05,{ }^{* *} P<0.01$ (Tukey's multiple comparison test).

Fig. 6. Effect of the 3D-microenvironment. (a) Fluorescent microscopic images of HUVEC monolayers exposed to media containing VEGF or collected from 1L-, 4L-, and 8L-NHDF tissues for 5 days. (b) CLSM images and (c) the total tubule length of each tissue after 7 days of incubation $(n=3)$. The HUVECs were immunostained with an anti-CD31 antibody (red). ${ }^{*} P<0.05$ when compared with $1 \mathrm{~L}-4 \mathrm{~L}$ (Tukey's multiple comparison test).

Fig. 7. MSC tissues with blood- and lymph-capillary networks. (a) Oxygen partial pressure of 1L-, 4L-, and 4L-MSC tissues under hypoxia during 36 hours of incubation $(n=3)$. (b) CLSM images and (c) the area of the tubule structures of each MSC tissue after 3 days of incubation $(n=3)$. ${ }^{*} P<0.05$, ${ }^{* *} P<0.01$ (Tukey's multiple comparison test). 
(a)

HUVEC with

FN-G nanofilm

NHDF with FN-G nanofilm
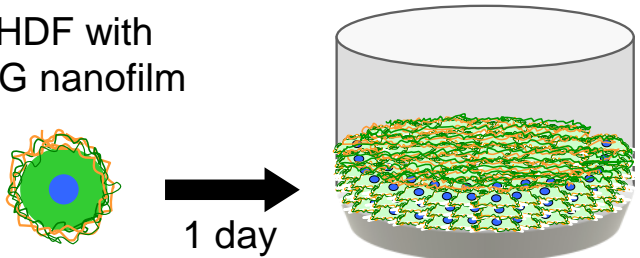

4L

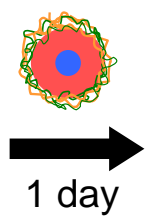

1 day

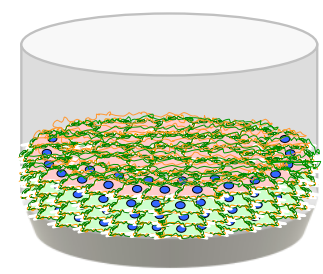

1L-4L
NHDF with FN-G nanofilm

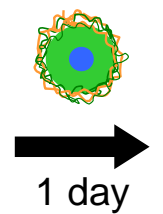

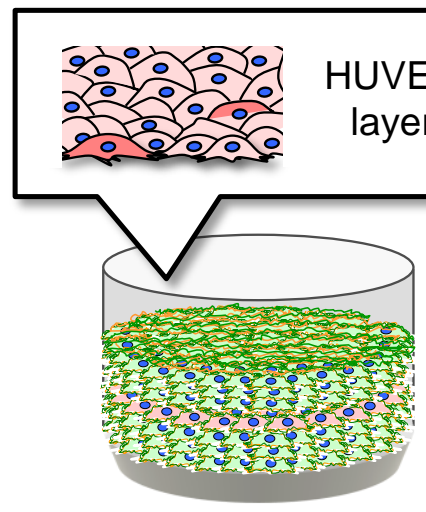

4L-1L-4L
Sandwich culture

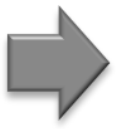

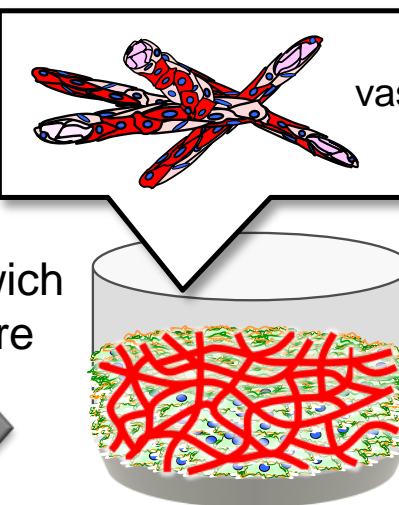

Blood-capillary model

- Number of layers

- Hypoxia conditions

- Angiogenic factors

-3D-microenvironments

(b)

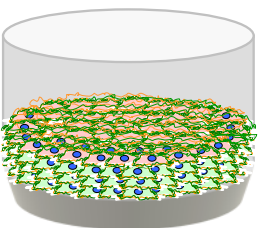

1L-4L

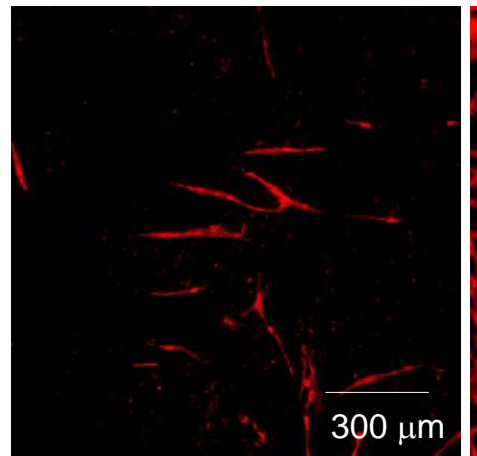

250

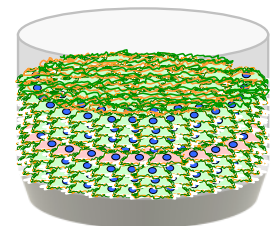

4L-1L-4L

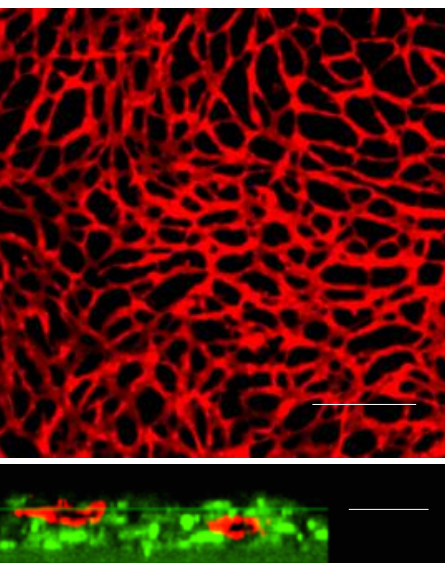

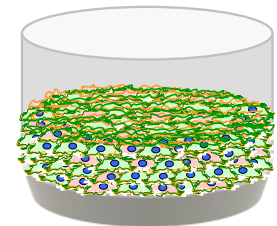

mixture

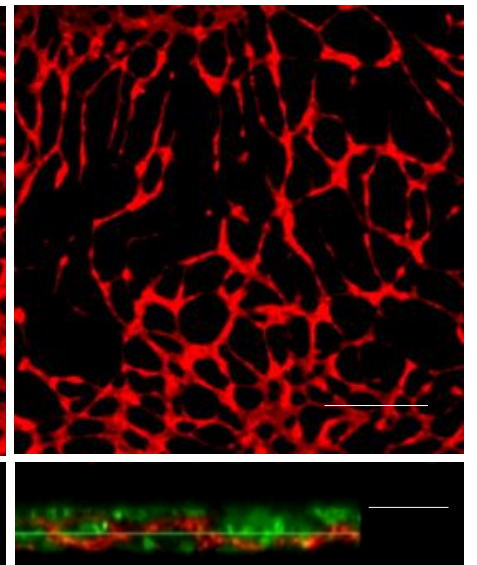

Figure 1. Nishiguchi et al. 
(a)

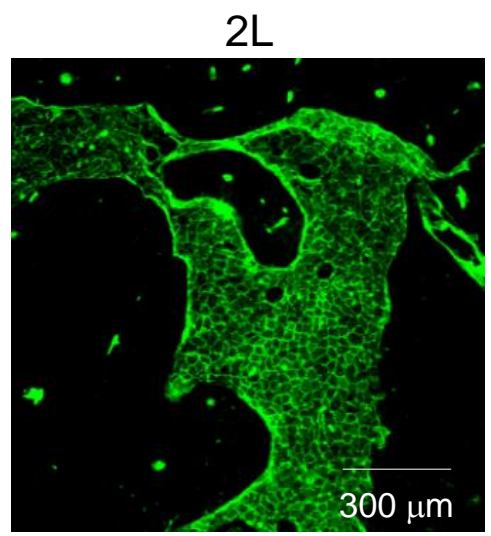

$8 \mathrm{~L}$

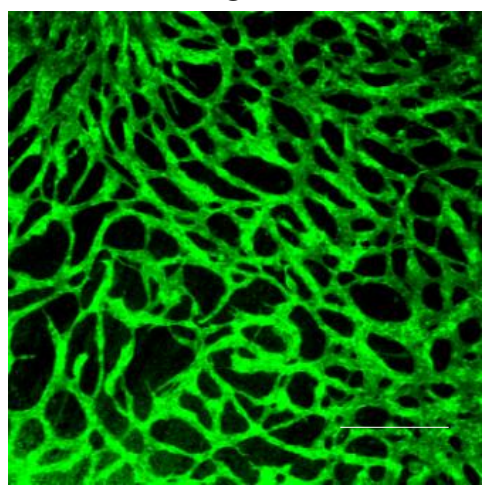

(b)

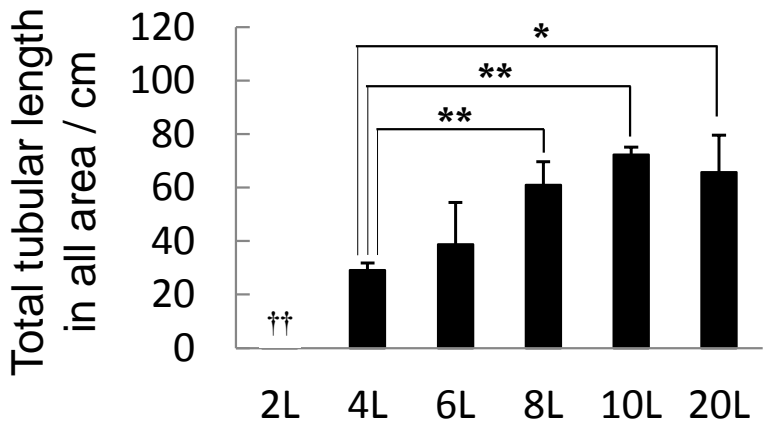

(d)

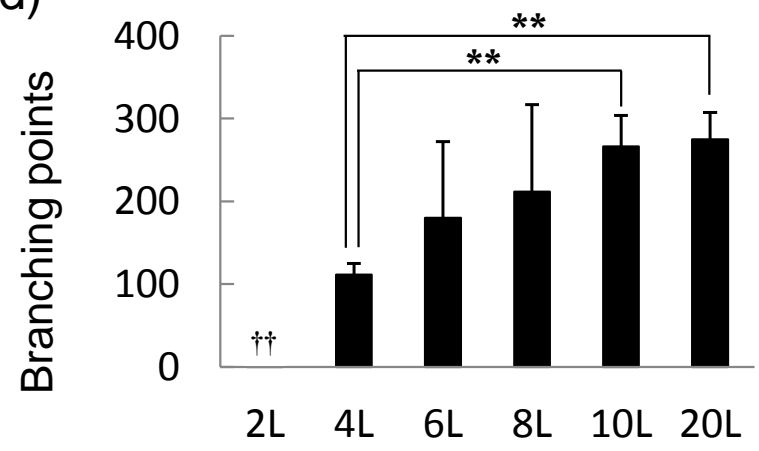

$4 \mathrm{~L}$

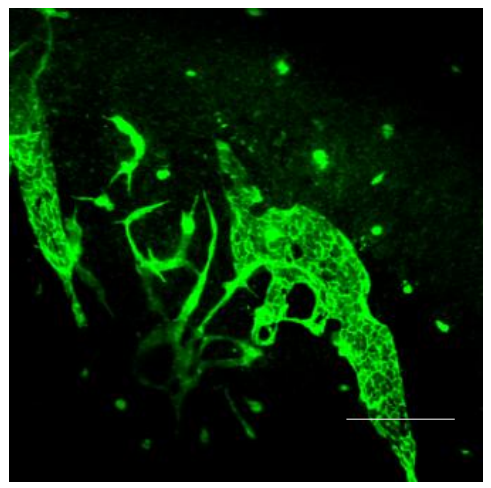

$10 \mathrm{~L}$

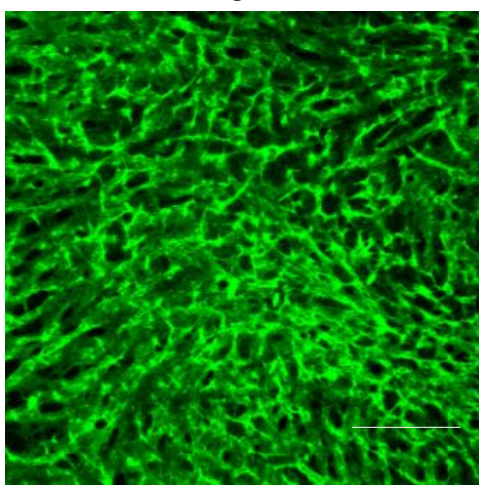

(c)

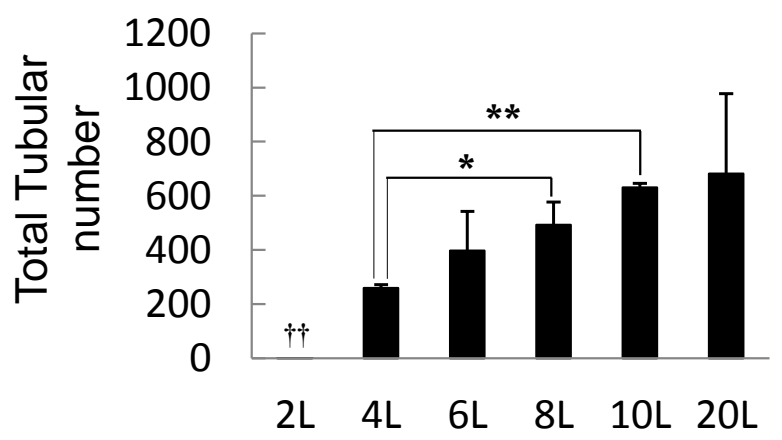

(e)
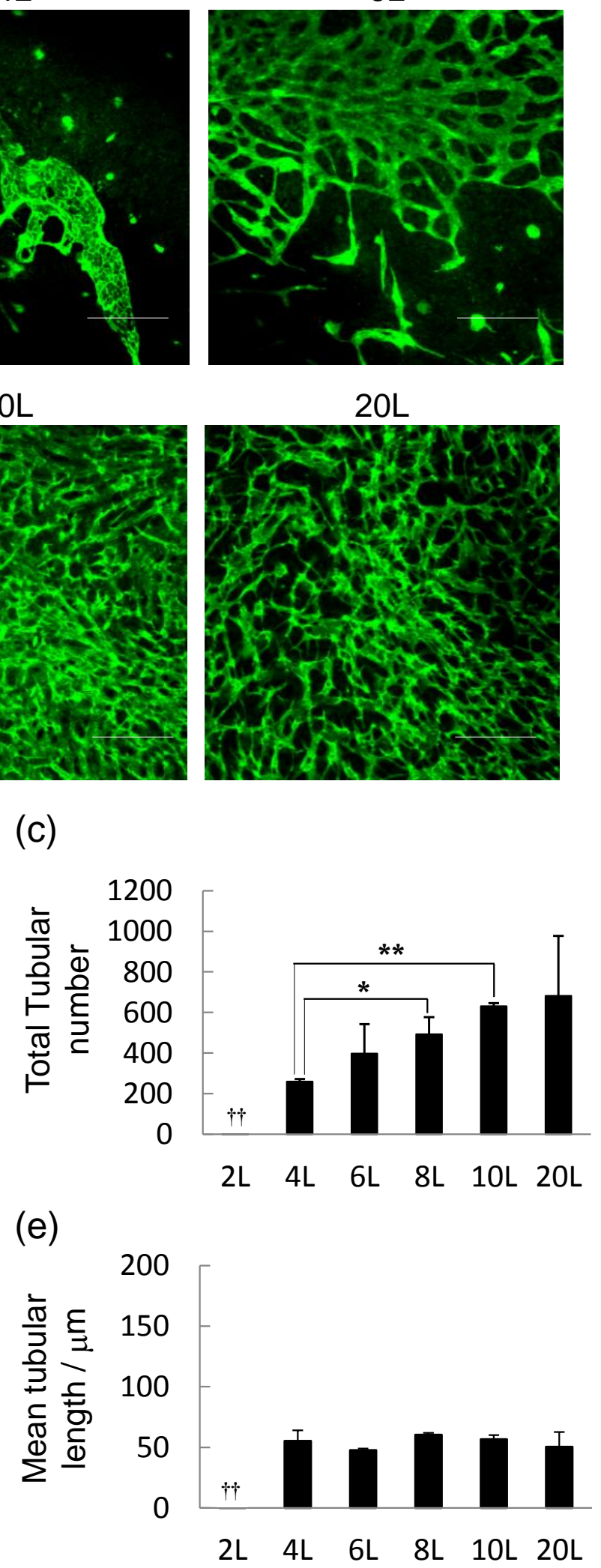

2L $\quad 4 \mathrm{~L} \quad 6 \mathrm{~L} \quad 8 \mathrm{~L} \quad 10 \mathrm{~L} \quad 20 \mathrm{~L}$

Figure 2. Nishiguchi et al. 
(a)

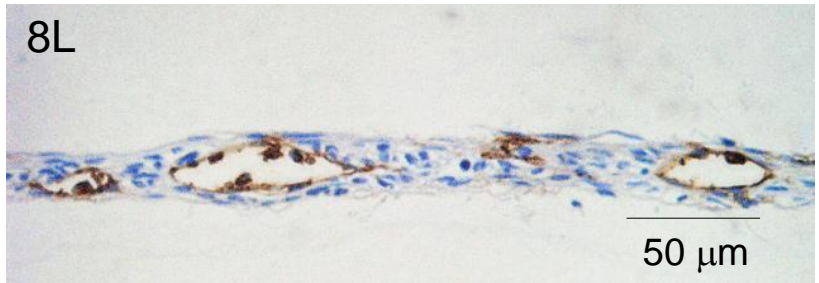

(c)

Collagen type IV

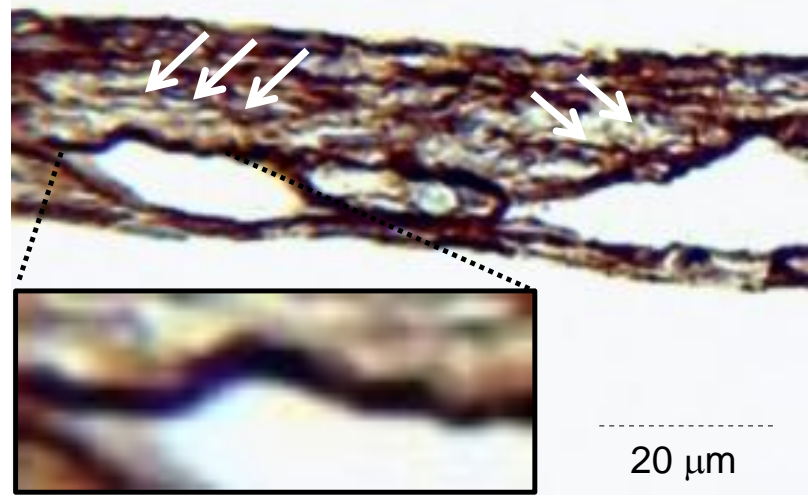

(e)

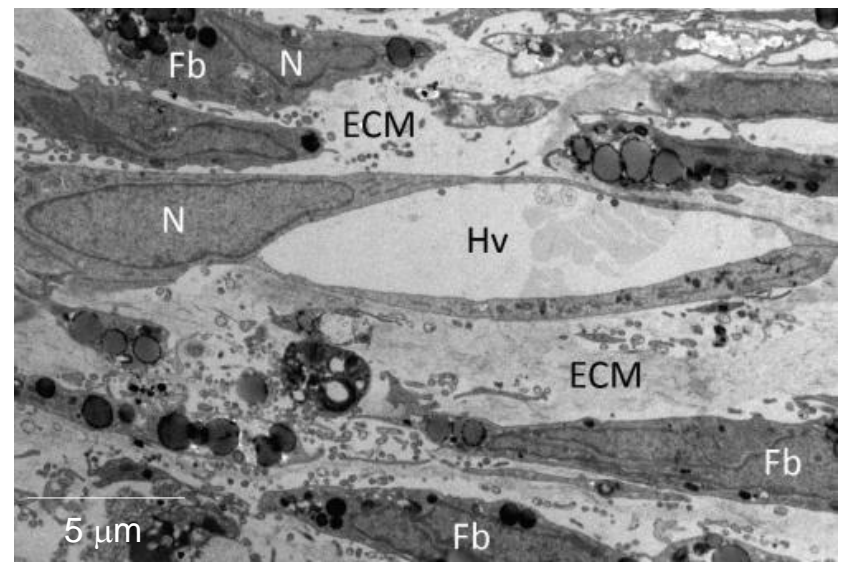

(b)

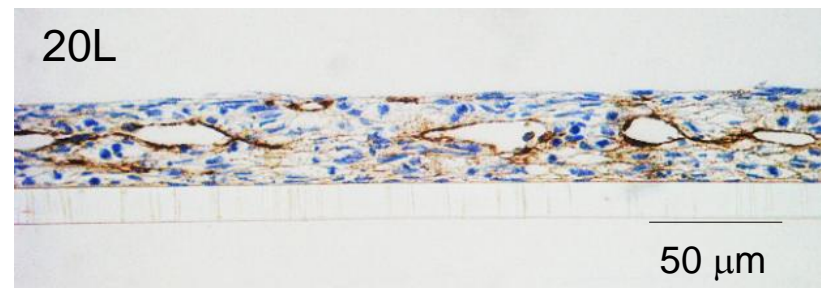

(d)

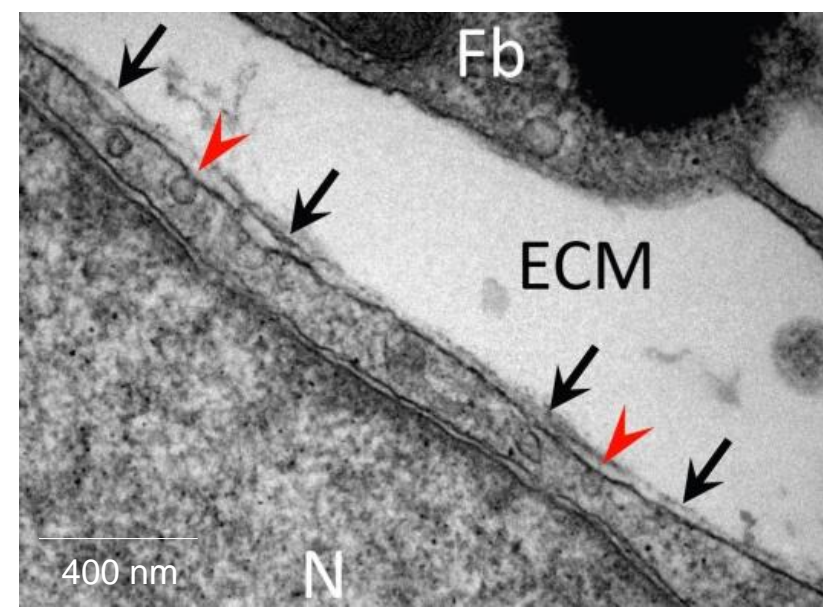

(f)

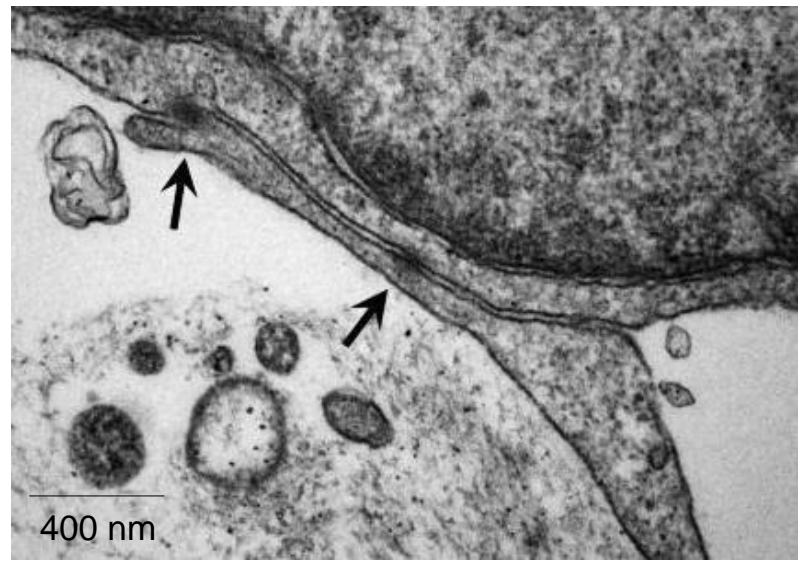

Figure 3. Nishiguchi et al. 
(a)

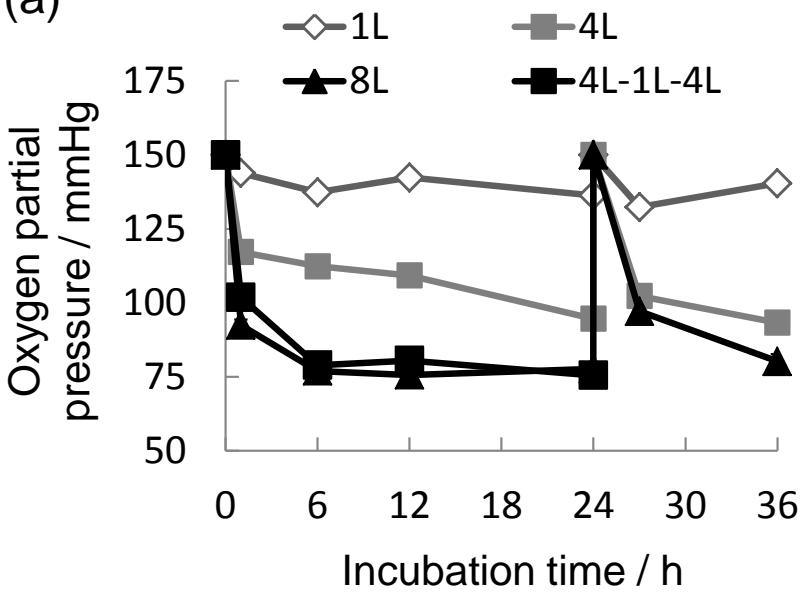

(c)

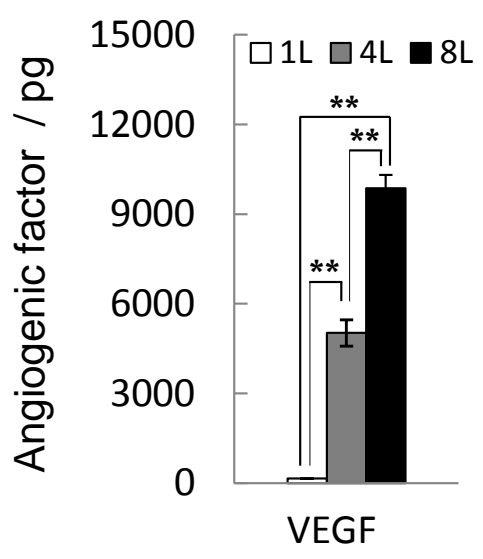

(f)

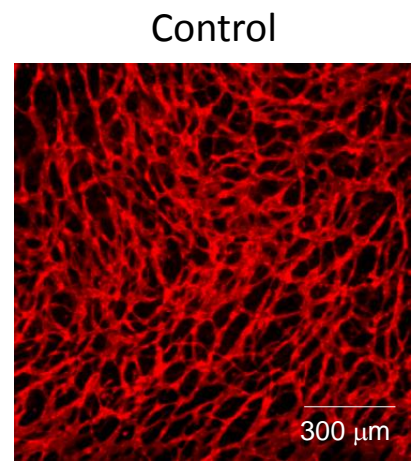

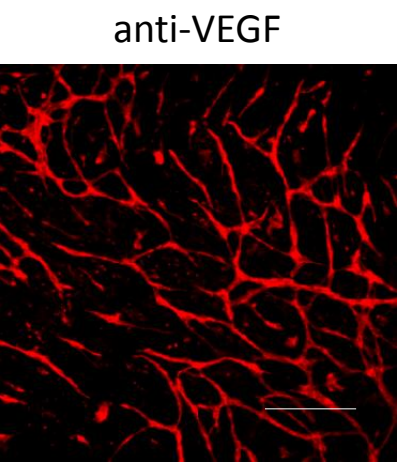

(d)

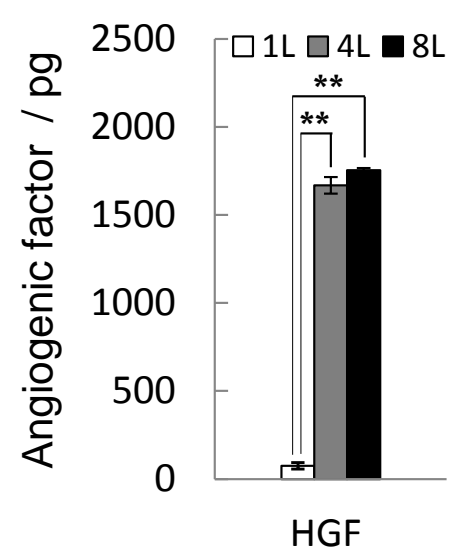

(g)

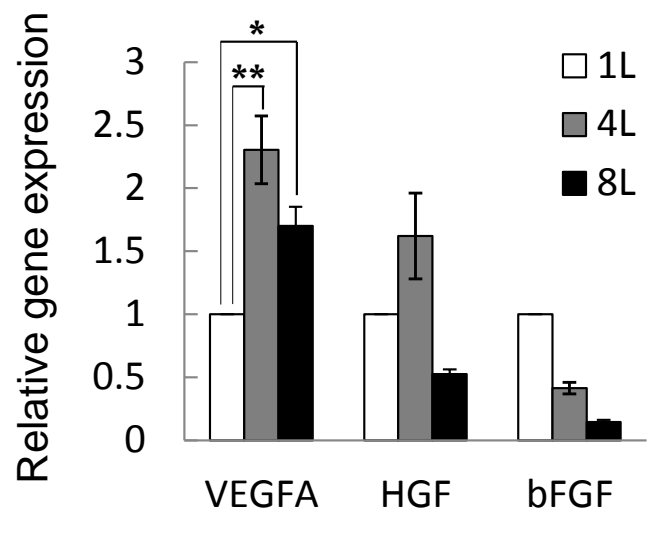

(e)

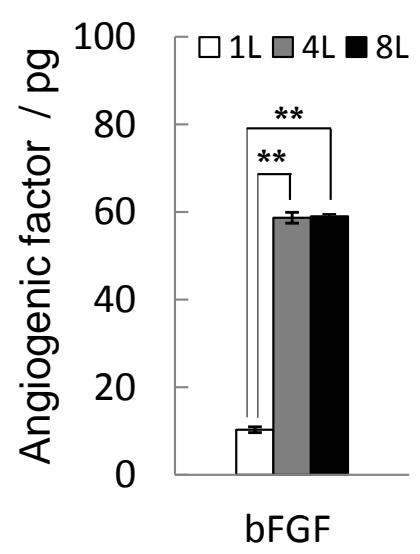

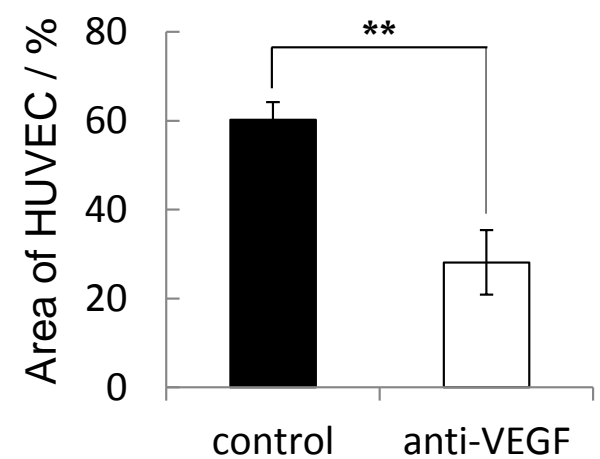

Figure 4. Nishiguchi et al. 
(a) VEGFA

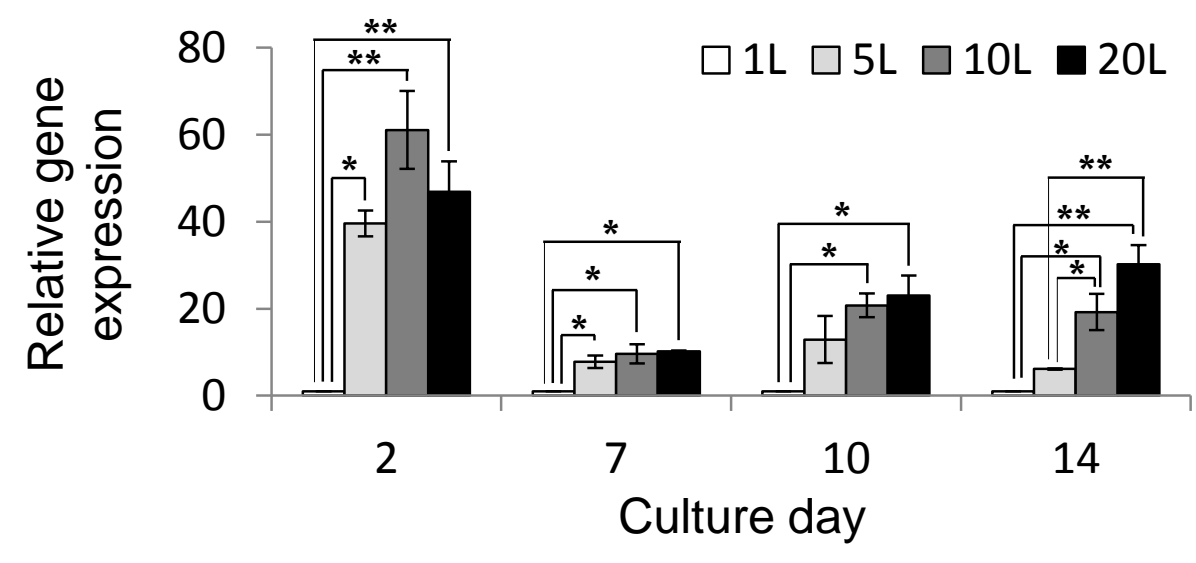

(b) HGF

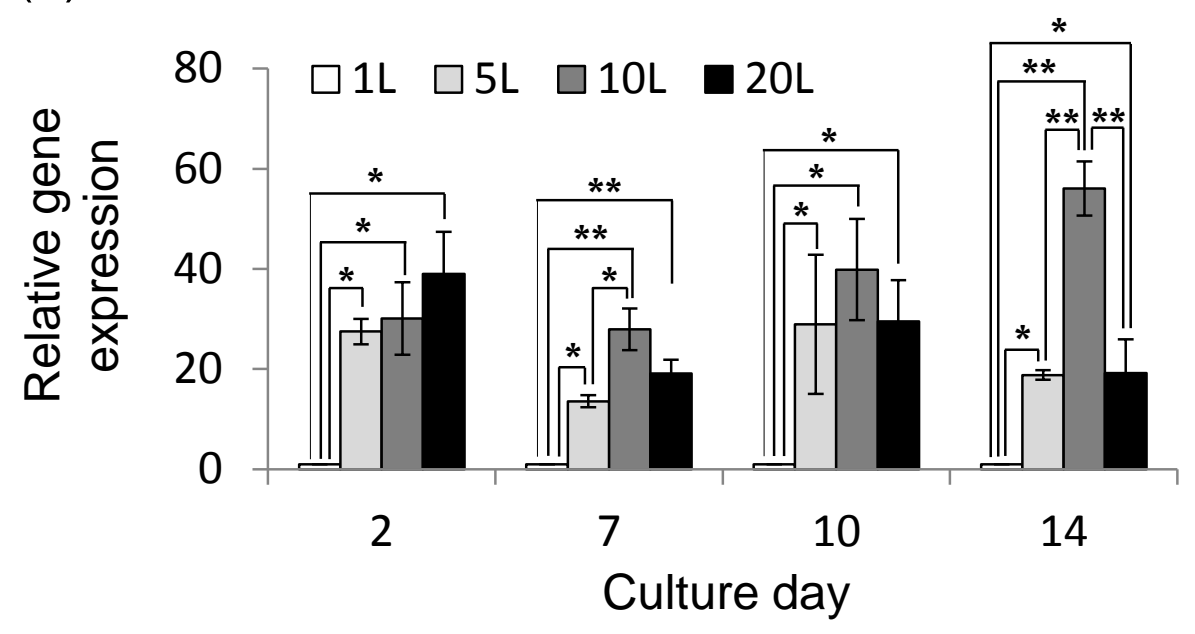

(c) bFGF

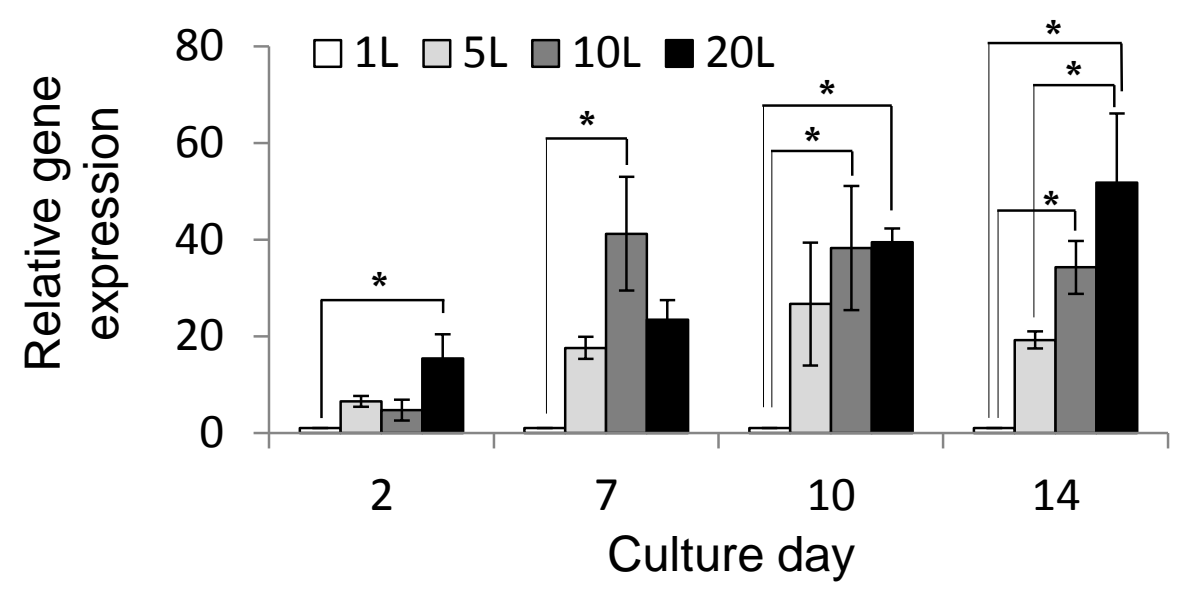

Figure 5. Nishiguchi et al. 
(a)
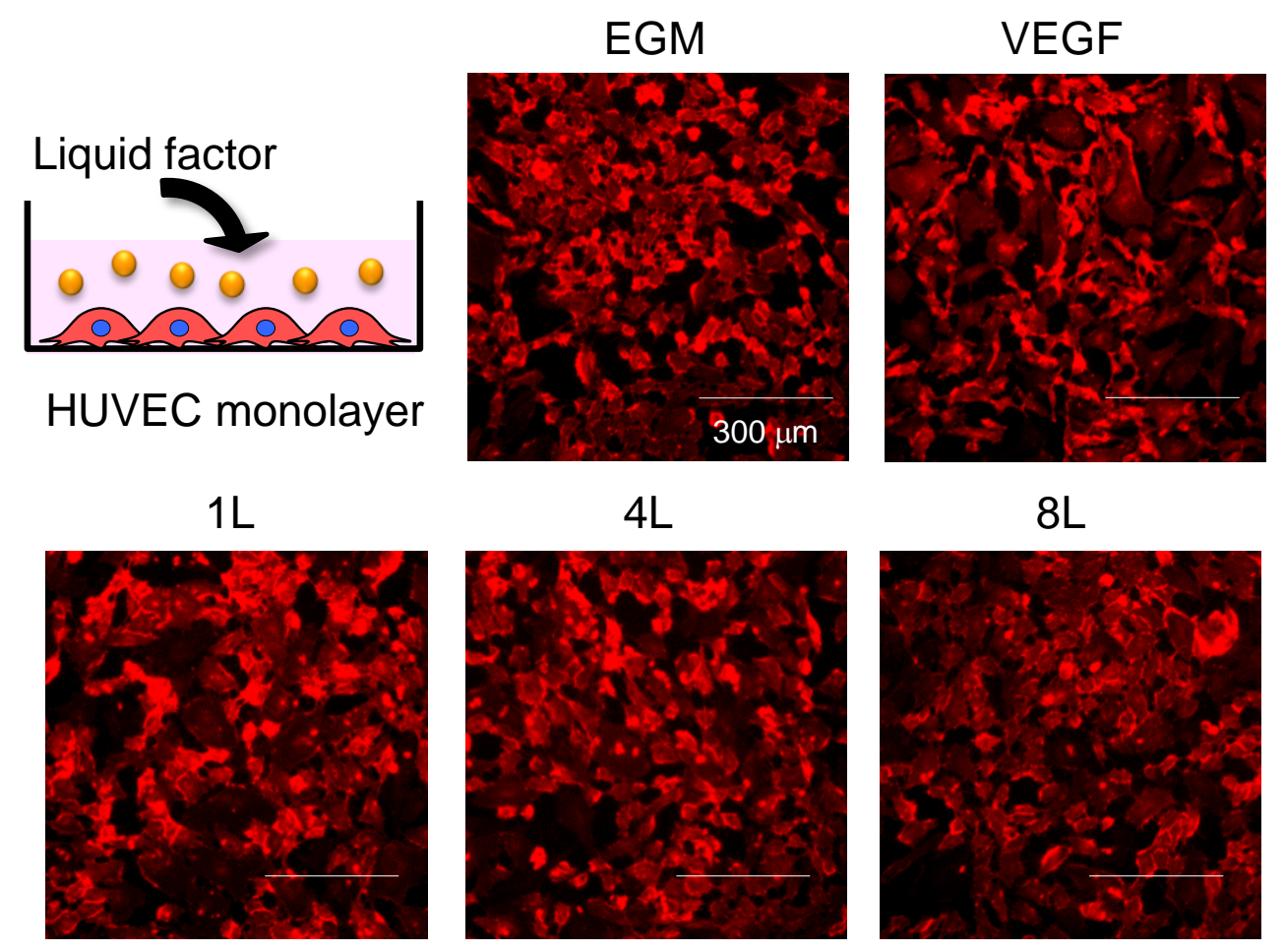

(b)
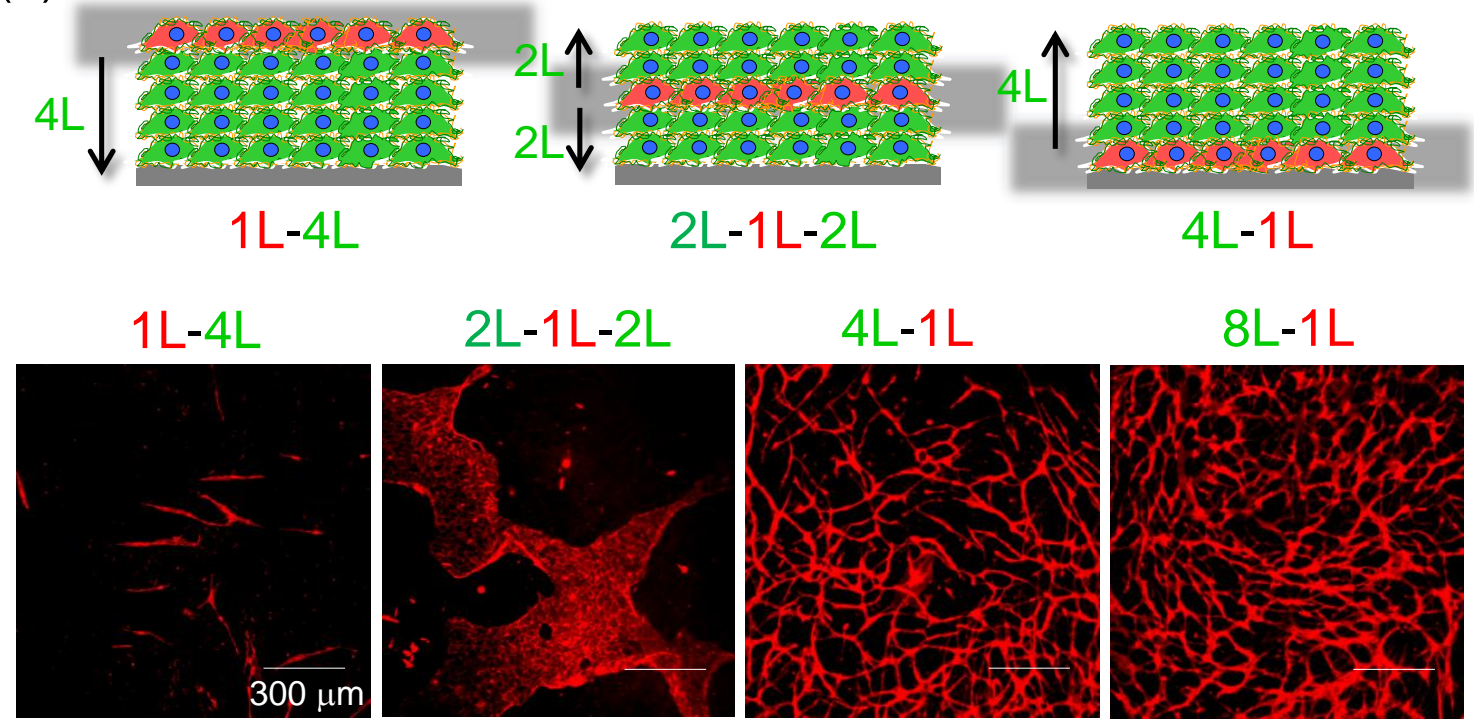

(c)

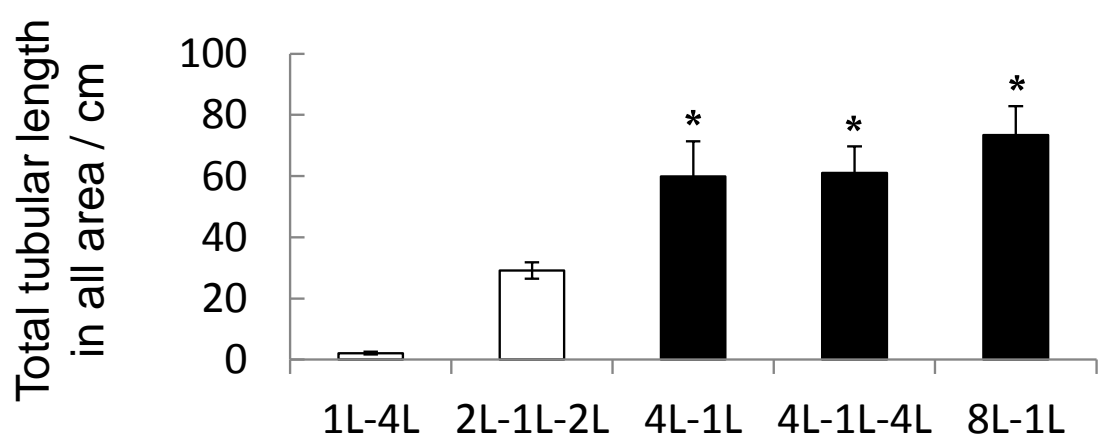

Figure 6. Nishiguchi et al. 
(a)

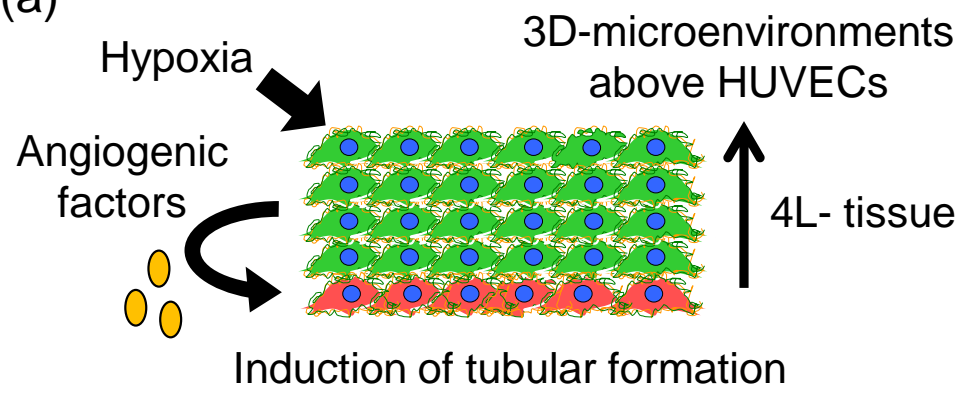

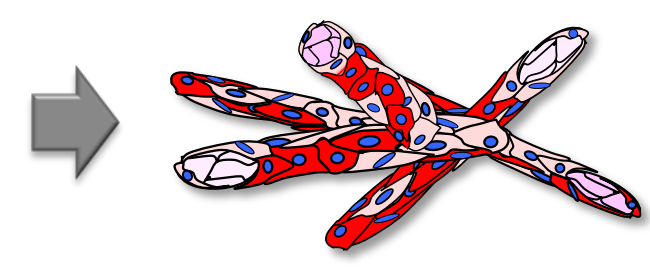

In vitro vascularization (b)

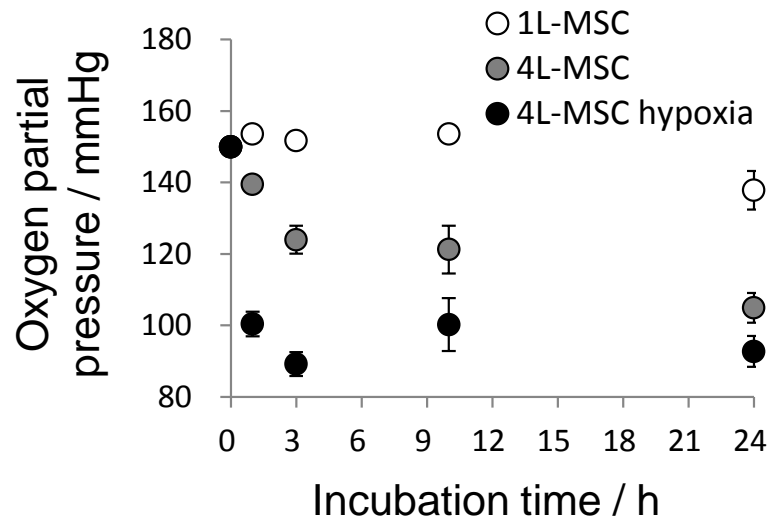

(c)

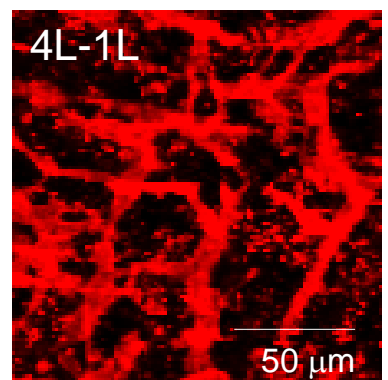

4L-1L + hypoxia

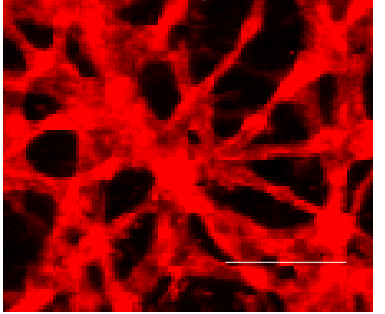

(d)

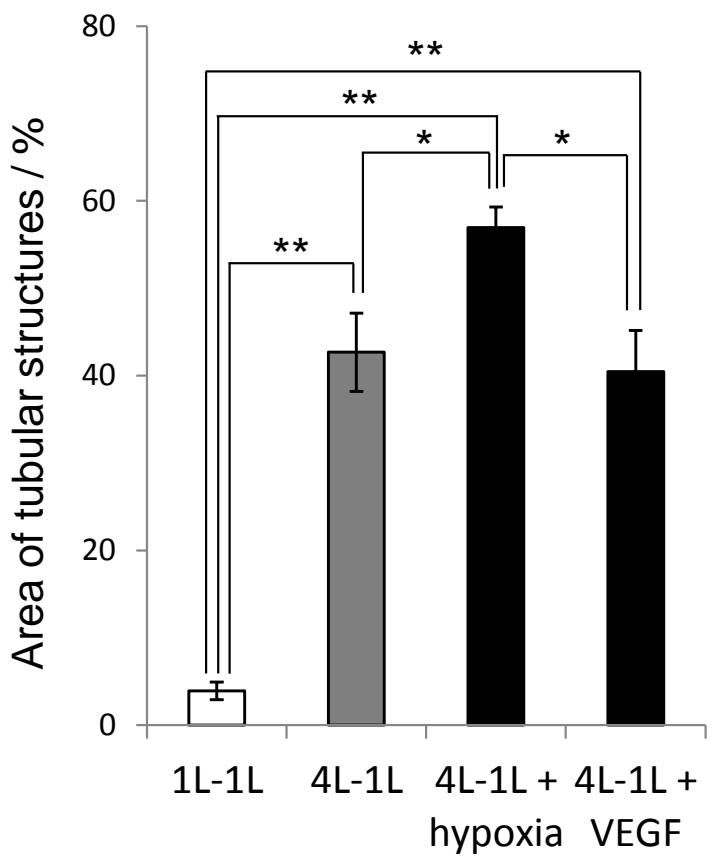

Figure 7. Nishiguchi et al. 